\title{
REVITALISASI \\ NILAI-NILAI AGAMA ISLAM \\ DALAM PENDIDIKAN AGAMA ISLAM DI PERGURUAN TINGGI
}

\author{
Tb. Chaeru Nugraha dan H.U. Jalaludin *)
}

\begin{abstract}
In this study, the author tried to compare the internalization of concepts and methods in the life of Islam at the time of Prophet Muhammad and at present time. At the level of concepts, the values of Islam during the life of Prophet Muhammad were still pure and clear that it could enlighten the community. Meanwhile, at present, some of the values of Islam have been infiltrated by the values of secularism, materialism. In such a case, it is necessary to revitalize the pure Islamic values as the foundation of life, including the intra-and inter-religious tolerance. Through learning the 'smart' (specific, measurable, achievable, relevant, and time framed) it is expected that the values of pure Islam will be easily realized. In one hand, at the level of methodology, the internalization of Islamic values at the time Prophet was performed comprehensively (kaffah). On the other hand, at present time, the method of internalization is performed partially and not integrated. It is expected that the revitalization of the concepts and methods of intemalization of Islamic values will be as closed as the methods applied at the time of Prophet Muhammad. First, the revitalization of the concept of aqeedah and Islamic values should cover all aspects of life. Second, the method of intemalizing the values of Islam should touch the cognitive, affective, and psychomotor aspects. Third, techniques of intemalization should be creative and innovative, using a various media, including insemination technology.
\end{abstract}

Keywords: Revitalization Concepts, Methods of Internalization, and Creative Techniques of Islamic Education.

\section{A. PENDAHULUAN}

Dikti (2006) dalam Rambu-Rambu Pelaksanaan MPK di PT telah merumuskan metodologi pembelajaran PAI. Antara lain, pada Pasal 5 Ayat 1 disebutkan bahwa metodologi MPK diselenggarakan secara interaktif, inspiratif, menyenangkan, menantang,

\footnotetext{
-) Tb. Chaeru Nugraha adalah dosen Pendidikan Agama Islam (PAI) Universitas Padjadjaran Bandung. H.U. Jalaludin adalah dosen Sastra Arab Universitas Padjadjaran.
} 
dan memotivasi peserta didik untuk berpartisifasi aktif, serta memberikan ruang yang cukup bagi prakarsa, kreativitas, dan kemandirian, dengan menempatkan mahasiswa sebagai subjek pendidikan, mitra dalam proses pembelajaran, dan sebagai umat, anggota keluarga, masyarakat dan warga negara.

Pada Pasal 5 Ayat 2 disebutkan, bahwa MPK proses pembelajarannya harus mendidik, sehingga terjadi pembahasan yang kritis, analitis, induktif, deduktif, dan reflektif melalui dialog kreatif partisipatori untuk mencapai pemahaman tentang subtansi dasar kajian, berkarya nyata, dan untuk menumbuhkan motivasi belajar sepanjang hayat. Pada Pasal 5 Ayat 3 disebutkan bahwa bentuk proses pembelajaran dapat dilakukan melalui beragam aktivitas, seperti kuliah tatap muka, ceramah, dialog (diskusi) interaktif, studi kasus, penugasan mandiri, penugasan kelompok, dan tugas kokurikuler (mentoring).

Walaupun secara konsepsi dan metodologi pembelajaran PAI di beberapa Perguruan Tinggi (PT) terlihat baik, namun masih meninggalkan beberapa permasalahan yang mendasar. Permasalahan tersebut antara lain: masih terjadinya tawuran antarmahasiswa, praktik pencontekan, perilaku asusila, kurangnya harmonisasi antarpenganut mazhab fikih-pemikiran-politik, dan hal-hal lain yang bertentangan dengan akhlak islami.

Pada tataran nasional, kita bisa memahami fakta masyarakat berdasarkan pernyataan mantan Menteri Agama Muhammad Maftuh Basyuni (Kompas, 29 Mei 2009), “....kerukunan umat beragama di Indonesia dinilai oleh dunia internasional sebagai yang terbaik... Bahkan Indonesia dianggap sebagai laboratorium kerukunan umat beragama. Paling tidak hal ini terungkap dari pernyataan Menlu Italia, Franco Frattini dan pendiri komunitas Sant' Egidio, Andrea Riccardi dalam pidatonya pada pembukaan seminar internasional dengan tema: Unity in Diversity: The Indonesian Model for a Society in which to Live Together, yang digelar pada 4 Maret 2009 di Roma".

Masih menurut Basyuni, yang dikutip Newsroom (31 Desember 2009) "...kerukunan umat beragama akan rentan dan terganggu apabila jurang pemisah antarkelompok agama dalam aspek-aspek sosial dan budaya ini semakin lebar, termasuk jurang- 
jurang pemisah sosial baru yang akan muncul akibat krisis moneter global saat ini. Pemeliharaan kerukunan umat beragama bukan hanya tanggungjawab para pejabat pemerintah di bidang agama dan pemuka agama, melainkan tanggung jawab seluruh lapisan masyarakat".

Objek penelitian ini adalah laporan evaluasi dan monitoring UPT Bidang Studi Agama Islam khususnya di Fakultas Ilmu Keperawatan (FIK), Fakultas Teknologi Industri Pertanian (FTIP), dan umumnya di Universitas Padjadjaran (Unpad) berdasarkan notulensi rapat dosen-dosen agama antara tahun 2009-2010. Pada tataran konsep UPT Bidang Studi Agama Islam Unpad, minimal ada dua buku rujukan utama, yaitu buku Wawasan al-Islam (2007) dan buku Mata Kuliah Pengembangan Kepribadian (2009). Buku Wawasan al-Islam memuat 16 bab materi pokok dan 5 materi suplemen. Sementara pada buku kedua terdiri dari 13 bab.

Kerangka teori dalam penelitian ini adalah metode deskriptifkomparatif dengan pendekatan eklektik. Penulis mencoba memperbandingkan konsep Islam pada masa Rasulullah SAW (Hisyam, 2004; dan Nabhany, 2002) dan masa kini (Tim Dosen, 2007 dan 2009). Pada tataran metode pembelajaran mengadaptasi model pembelajaran terpadu (Karel, 2002), observasi dan diskusi teman sejawat (Lincoln dan Guba, 1985) serta mengadopsi triangulasi metodologi Cohen dan Manion (1994). Triangulasi metodologi dilakukan dengan memanfaatkan berbagai sumber yang relevan seperti buku-buku tafsir dan as-sunnah, antara lain: Tafsir al-Qur'an As-Shabuny (1989), Ilmu-Ilmu al-Qur'an Abu Rusytha (2006), Qaththan (2001), maktabah syamilah, dan pustaka 9 kitab Hadis.

Berdasarkan data tersebut di atas, penulis mencermati bahwa akar masalah dari berbagai masalah sosial budaya yang memicu ketidakrukunan intra dan antarumat beragama, baik di kampus khususnya, maupun di masyarakat, antara lain: (1) adanya missing link paradigma akidah Islam dengan realitas kehidupan; (2) kurangnya pemahaman terpadu nilai-nilai Islam dan aplikasi muamalah dalam kehidupan sehari-hari; dan (3) kurangnya variasi komunikasi dinamis pendidik dan peserta didik. Untuk keperluan 
Tb. Chaeru Nugraha \& H.U. Jalaludin: Revitalisasi Nilai-nilai Agama Islam dalam PAI...

tersebut kita perlu melihat qudwah hasanah Rasulullah sebagai pendidik umat terbaik sepanjang sejarah sebagai intisari parameter suksesnya pendidikan Islam masa kini. Beliaulah, pemimpin multikultur dengan standar ilahiyah di Madinah Munawwarah.

\section{B. KOMPARASI KONSEPSI PENDIDIKAN AGAMA ISLAM}

Sebelum membahas konsep pendidikan agama Islam, sebaiknya kita mengetahui hakikat ilmu pengetahuan menurut Islam. Hakikat ilmu pengetahuan dalam al-Qur'an /ilmi/, antara lain dapat dipahami dari 58 ayat dengan berbagai bentuk derivasinya ('alima, 'allama, ilm, dll). Dari 58 ayat yang termasuk makkiyyah (turun sebelum Nabi Muhammad SAW hijrah dari Makkah) ada 42 ayat dan sisanya 16 termasuk ayat madaniyyah (turun setelah Rasulullah SAW hijrah ke Madinah). Ayat-ayat makkiyyah umumnya membicarakan tentang konsep ilahiah, keimanan kepada al-Qur'an dan masalah ghaib, serta kisah umat Nabi-nabi terdahulu. Konsep ilmu pada ayat-ayat makkiyyah dapat dipahami berdasarkan Tabel 1 sebagai berikut:

Tabel 1. Konsep Ilmu Pada Ayat-Ayat Makkiyyah

\begin{tabular}{|c|l|l|l|}
\hline No & \multicolumn{1}{|c|}{ Surat Ayat } & \multicolumn{1}{|c|}{ Nuzul } & \multicolumn{1}{|c|}{ Tema } \\
\hline 1 & al-An'am(6):100 & Makkiyyah & $\begin{array}{l}\text { Orang musyrik tidak mengetahui } \\
\text { hakikat Allah. }\end{array}$ \\
\hline 2 & al-An'am(6):108 & Makkiyyah & $\begin{array}{l}\text { Allah akan menginformasikan setiap } \\
\text { perbuatan manusia (penyimpangan } \\
\text { asumsi tanpa dasar wahyu) }\end{array}$ \\
\hline 3 & al-An'am(6):119 & Makkiyyah & $\begin{array}{l}\text { Allah Maha mengetahui orang-orang } \\
\text { yang melampaui batas (menyalahi halal- } \\
\text { haram) }\end{array}$ \\
\hline 4 & al-An'am(6):140 & Makkiyyah & $\begin{array}{l}\text { Tanpa ilmu (mengenal Allah), manusia } \\
\text { akan tersesat. }\end{array}$ \\
\hline 5 & al-An'am(6):144 & Makkiyyah & $\begin{array}{l}\text { Tanpa ilmu (mengenal Allah), manusia } \\
\text { akan mudah dibohongi. }\end{array}$ \\
\hline 6 & al-An'am(6):148 & Makkiyyah & $\begin{array}{l}\text { Tanpa ilmu (mengenal Allah), manusia } \\
\text { hanya menduga-duga. }\end{array}$ \\
\hline 7 & al-A'raf(7):52 & Makkiyyah & $\begin{array}{l}\text { Al-Quran sumber ilmu pengetahuan, } \\
\text { petunjuk kehidupan dan kasih sayang } \\
\text { Allah. }\end{array}$ \\
\hline 8 & al-A'raf(7):160 & Makkiyyah & $\begin{array}{l}\text { Kisah umat Nabi Musa mengetahui } \\
\text { tempat (minum) masing-masing. }\end{array}$ \\
\hline 9 & Hud(11):46 & Makkiyyah & $\begin{array}{l}\text { Kisah putra Nabi Nuh yang ingkar, } \\
\text { hakikatnya bukan keluarga Nabi Nuh. }\end{array}$ \\
\hline 10 & Hud(11):47 & Makkiyyah & $\begin{array}{l}\text { Allah Maha Mengetahui hakikat segala } \\
\text { sesuatu. }\end{array}$ \\
\hline
\end{tabular}


Tb. Chaeru Nugraha \& H.U. Jalaludin: Revitalisasi Nilai-nilai Agama Islam dalam PAI...

\begin{tabular}{|c|l|c|l|}
\hline No & \multicolumn{1}{|c|}{ Surat Ayat } & \multicolumn{1}{c|}{ Nuzul } & \multicolumn{1}{|c|}{ Tema } \\
\hline 11 & Yusuf(12):68 & Makkiyyah & Kisah Nabi Ya'kub dan anak-anaknya. \\
\hline 12 & Yusuf(12):76 & Makkiyyah & $\begin{array}{l}\text { Kisah Nabi Yusuf dan saudara- } \\
\text { saudamya. }\end{array}$ \\
\hline 13 & ar-Ra'du(13):43 & Makkiyyah & $\begin{array}{l}\text { Persaksian Nabi Muhammad SAW } \\
\text { tentang ilmu Allah. }\end{array}$ \\
\hline
\end{tabular}

Pada ayat-ayat makkiyyah tersebut di atas, tersirat pesan kepada kita -para pendidik, orang tua, dan para pemimpin- agar menanamkan akidah tauhid kepada anak-anak, peserta didik, dan masyarakat pada umumnya. Pada masa Rasulullah SAW, beliau mengajarkan dan menanamkaan akidah tauhid sebagai landasan kehidupan. Hal ini antara lain terungkap melalui Hadits Arbain ke-19 dalam Al-Wafi fi Syarhi al-Arba'in An-Nawawiyah. Diriwayatkan dari Ibnu Abbas Abdillah bin Abbas ra., ia bertutur: "Suatu hari aku berada di belakang Rasulullah SAW. Lalu beliau bersabda: 'Nak! Aku hendak mengajarkan kepadamu beberapa kalimat. Jagalah Allah, Ia akan menjagamu; jagalah Allah, niscaya engkau dapatkan Dia mengokohkanmu; bila engkau meminta, mintalah kepada Allah; bila engkau memohon pertolongan, mohonlah pertolongan kepada Allah. Ketahuilah bahwa jika seluruh umat ini berkumpul untuk memberikan sesuatu yang bermanfaat bagimu, maka mereka tidak akan bisa memberi manfaat kepadamu kecuali dengan sesuatu yang telah ditetapkan oleh Allah untukmu. Dan jika seluruh umat ini berkumpul untuk memudharatkanmu dengan sesuatu, maka mereka tidak akan bisa memudharatkanmu kecuali dengan sesuatu yang telah ditetapkan oleh Allah terhadapmu. Pena-pena telah diangkat dan lembaranlembaran telah ditutup.'”

Beberapa pokok penjelasan hadits tersebut, antara lain: Pertama, bahwa Nabi SAW mengajarkan bahwa semua perkara ada dalam ilmu Allah; Kedua, dengan metode yang menggugah, beliau berhasil menjadikah akidah sebagai kaidah berpikir; Ketiga, kaidah berpikir tauhid memotivasi manusia untuk melaksanakan semua perintah Allah dan menjauhi larangan-Nya; Keempat, dengan mentaati Allah niscaya mendapat pertolongan Allah di dunia dan akhirat; dan Kelima, beliau menjadikan akidah tauhid sebagai panduan kehidupan. Singkatnya, berdasarkan penjelasan 
Hadis tersebut di atas kita mendapatkan intisari konsep pendidikan Nabi SAW dalam mengajarkan akidah tauhid.

Akidah tauhid yang diajarkan Rasulullah memiliki karakteristik, yaitu: 1) dibangun berdasarkan dalil aqly-naqly (akal-nash), 2) sesuai dengan fitrah manusia, 3) bersifat syumuliy (holistik) mencakup dunia akhirat, dan 4) tsabitah (kokoh). Indikator keberhasilan akidah tauhid mencakup dua dimensi, yaitu dimensi spiritual (ruhiyah) dan dimensi realis (nazhra al-hayat). Para sahabat yang dibina oleh Rasulullah SAW memiliki keikhlasan yang murni. Hasil pembinaan ini terlihat pada kepribadian sahabat yang berakhlak mulia dan memiliki cara pandang kehidupan yang istimewa sehingga kreatif, inovatif, produktif, dan hidup berkah. Hubungan kedua dimensi tersebut dapat dipahami secara singkat berdasarkan Gambar 1, sebagai berikut:

\section{Gambar 1. Dimensi Akidah Tauhid}

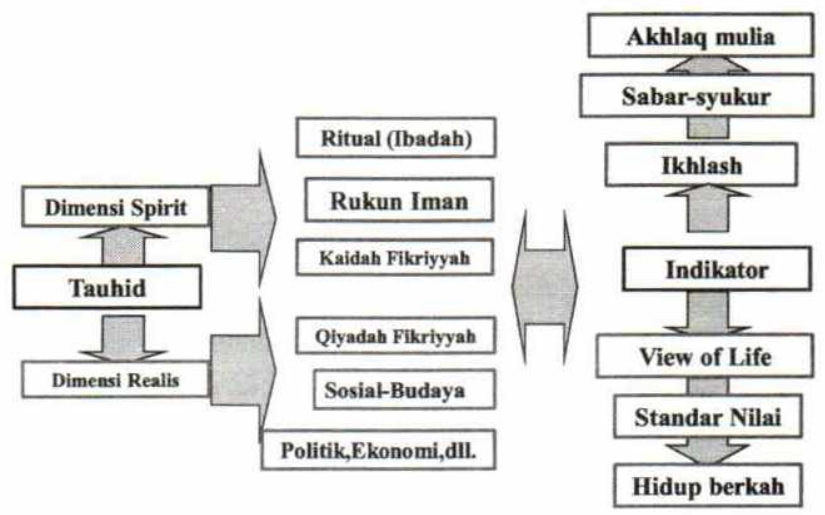

Dengan demikian, semakin manusia memahami hakikat ilmu pengetahuan, dia akan semakin tunduk pada hukum Allah (Q.S. [35]:27-28). Secara umum, mahasiswa saat ini sudah memahami tauhid sebagai landasan ibadah ritual dan moral. Hanya saja pemahaman tersebut belum menjadi bagian dari paradigma berpikir dan bersikapnya. Oleh karena itu, mahasiswa perlu mendapatkan deskripsi pemikiran Islam dalam konsep jati dirinya.

Pada tataran paradigma berpikir Islam sebagai ide, menurut Husain (2002: 12), memiliki empat karakter: komprehensif 
(syumuly), dapat dikembangkan (ittisa'), praktis ('amaly), dan manusiawi (insany). Islam bersifat komprehensif artinya pemikiran Islam mengatur semua aspek kehidupan manusia, seperti politik, sosial kemasyarakatan, perekonomian, kebudayaan, dan akhlaq. Allah berfirman antara lain dalam Q.S. An-Nahl (16): 89, yaitu:

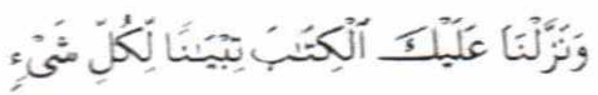

89. ....dan Kami turunkan kepadamu Al kitab (Al Quran) untuk menjelaskan segala sesuatu. Selanjutnya, perhatikan Gambar 2,

Gambar 2. Islam Sebagai Ide dan Metode

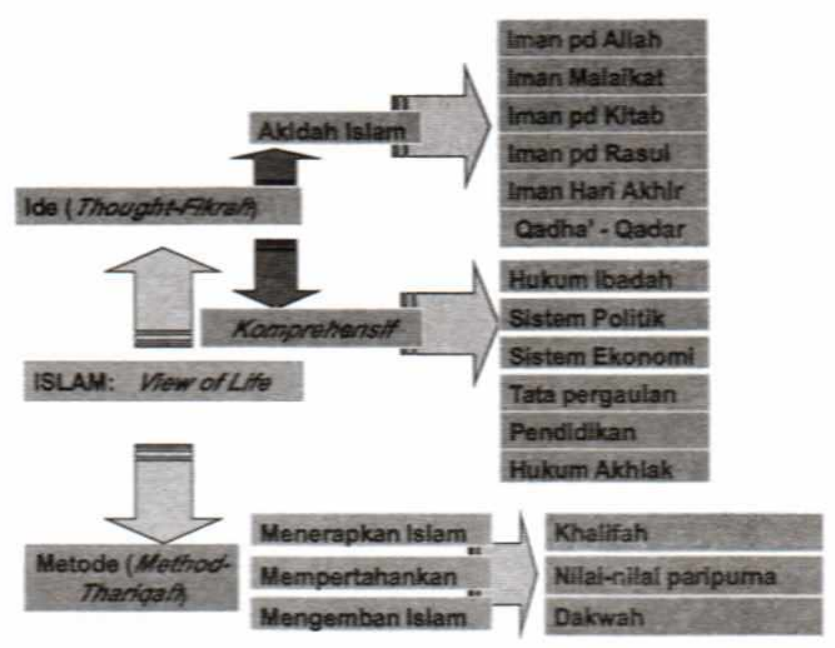

Islam sebagai metode kehidupan tergambar dalam kehidupan Rasulullah SAW dan para sahabatnya. Para khalifah melanjutkan kehidupan Islam dengan meneladani metodenya dalam internalisasi nilai-nilai Islam (Husain, 2002:149). Dalam setiap aktivitasnya, seorang muslim pasti memiliki minimal salah satu dari target nilai, baik nilai material, spiritual, moral, atau kemanusiaan.

Aktivitas muslim yang mengandung target nilai material antara lain: bekerja, bertani, dan berdagang (Q.S. [2]:257). Aktivitas salat, membaca al-Qur'an, dan ibadah-ibadah ritual target merupakan nilai yang bersifat spiritual agar semakin dekat dengan Allah (Q.S. [98]:5). Berbeda dengan belajar ilmu biologi, ilmu fisika, keterampilan, dan ilmu pengetahuan pada umumnya, 
target nilainya adalah meningkatkan nilai kemanusiaanya (Q.S. [58]:11). Adapun jujur, berani, wara', sabar, dan syukur dalam menghadapi kehidupan, maka targetnya meningkatkan nilai moral. Semua aktivitas seorang muslim dengan nilai yang diraihnya didedikasikan untuk beribadah dan menjadi khalifah di muka bumi (Q.S.[51]:56 dan Q.S.[2]:30).

Pada saat ini, nilai dalam pandangan masyarakat sekuler kapitalis hanyalah nilai material. Mereka tidak memandang sedikitpun nilai spiritual, nilai kemanusiaan, dan nilai moral, kecuali bila ada keuntungan secara material. Satu di antara fakta yang bisa kita amati adalah ketika dosen bertanya kepada para mahasiwa tentang tujuan mereka kuliah. Pada umumnya jawaban mereka antara lain: mendapat prestasi akademik agar setelah lulus mereka dapat pekerjaan yang layak. Padahal, bila kita memahami kehidupan Rasulullah dan para sahabat, tujuan pendidikan adalah terbentuknya manusia seutuhnya, yaitu berkepribadian islami dan memiliki keterampilan untuk berperan sebagai rahmatan lil'alamin dalam kehidupan.

Gambar 3. Kepribadian Islam

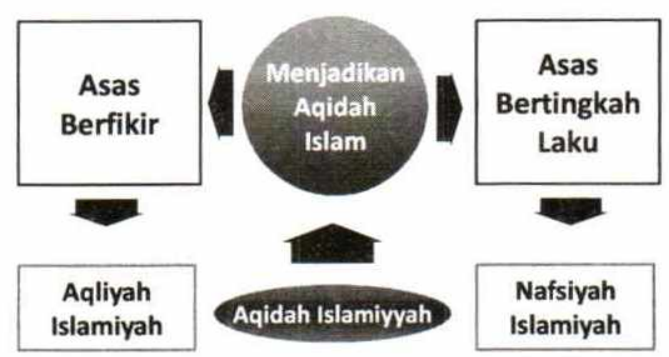

Berdasarkan pengamatan, kita menyaksikan masih ada mahasiswa maupun anggota masyarakat umumnya, yang nilai PAI-nya bagus atau lulusan PTI. Terkadang terjadi perilakunya bertolak belakang dengan pemahaman mereka. Ini menunjukkan tidak cukup seorang muslim berpola pikir islam saja, tapi perlu pelatihan agar berpola sikap islami. Di sinilah diperlukan metode terpadu dalam upaya internalisasi nilai islam baik dalam pendidikan formal, informal, maupun nonformal. 


\section{METODE PENDIDIKAN ISLAM TERPADU}

Kehidupan Islam yang paripurna tergambar dalam kehidupan Rasulullah SAW dan para sahabatnya. Satu di antara cuplikan cahayanya terlihat dalam khutbah haji wada Rasulullah SAW: "Sesungguhnya darah (jiwa) dan harta bendamu adalah terpelihara atau haram atas kamu (mengganggunya) sebagaimana haramnya hari ini di bulan dan di tempat ini. Ketahuilah! Semua persoalan yang terjadi di jaman jahiliyah .... mulai hari ini dihapuskan ...... Sesungguhnya aku tinggalkan untuk kamu sesuatu yang kamu tidak akan sesat sesudahnya, jika kamu berbegang teguh padanya, yaitu Kitabullah (Hisyam, 2004; dan Gayo, 2002).

Berdasarkan penjelasan Hadis tersebut, digambarkan pula bagaimana hubungan Rasulullah SAW dan para sahabat luar biasa indah. Tatkala beliau mempersilahkan qishash pada dirinya, bila ada di antara para sahabat yang pernah tersakiti. Inilah ibrah (pelajaran) bagaimana seharusnya hubungan antara dosen dan mahasiwa yang setara dan santun. Sebagaimana pula metode Rasulullah dalam pembelajaran Islam.

Metode Rasulullah SAW dalam pembelajaran Islam ada tiga prinsip (Nabhany, 2002). Pertama, memahami Islam secara komprehensif (aspek kognitif). Kedua, meyakini Islam sebagai solusi kehidupan (aspek afektif). Ketiga, melatih melaksanakan perintah-perintah Allah dan Rasul-Nya serta menjauhkan diri dari berbagai larangan-Nya (aspek psikomotorik). Untuk mewujudkan ketiga prinsip tersebut diperlukan metode terpadu.

Beberapa ciri metode terpadu mengadaptasi pendapat Karli (2002:15) antara lain: 1) holistik, contohnya kasus "video mesum Ariel" dikaji realitanya dari berbagai aspek seperti aspek sosial kemasyarakatan, kesehatan jiwa, dan agama; 2) signifikan (bermakna), keterkaitan dengan konsep-konsep lain yang dipelajari mahasiswa, sehingga terbangun kemampuan memberikan solusi bagi berbagai permasalahan dalam kehidupannya; dan 3) aktif, mahasiswa dituntun untuk membaca berbagai referensi, memformulasikannya, dan menyajikan presentasi yang akan ditanggapi oleh teman-teman sekelasnya. 
Pada tataran praktis, ketiga prinsip tersebut bisa dicapai dengan berbagai metode, antara lain: metode training, metode diskusi, metode hidmah masyarakat, metode ceramah, dialektika, dan lain-lain. Pada pertemuan pertama, dosen menyampaikan visi dan misi pendidikan agama Islam (PAI) di perguruan tinggi. Selain itu, untuk memahami keberagaman pemahaman (kognitif) mahasiswa, dosen meminta mahasiswa untuk menuliskan tentang apa saja buku agama Islam yang telah dibaca, aktivitas kajian keagamaan yang sering dilakukan, dan interaksi mereka dengan masjid terdekat dengan tempat tinggalnya. Pada waktu itu, dosen pun berusaha mengetahui faktor afeksi (penghayatan keagamaan) mahasiswa melalui uji petik pemaknaan salat. Mahasiwa diminta menuliskan salah satu arti bacaan salatnya. Pada lembar kerja yang sama, mahasiwa dimotivasi untuk merencanakan suatu amal shaleh yang berdampak sosial di tengah masyarakat. Pada tahap selanjutnya mahasiswa telah memiliki study club untuk melatih ketiga prinsip pembelajaran Islam.

Metode penunjang dalam PAI adalah metode training. Metode ini dirancang bersama dengan mahasiswa dengan menggunakan multimedia. Metode training saat ini banyak dipergunakan dalam membangun kerangka berpikir dan sikap yang berkarakter. Metode training dapat mengoptimalkan seluruh jenis pembelajaran (audio, visual, akomodatif, dan demonstratif).

Pelaksanaan training PAI bisa dilakukan pada pertemuan kedua, menjelang tengah semester atau akhir semester, disesuaikan dengan tema yang hendak diangkat. Contohnya training dengan tema "Islam Rahmatn lil-'Alamin". Tahap pertama, dosen sebagai Trainer (T) memberikan arah dan tujuan training ini dengan audio-visual yang menarik. Kemudian menginformasikan aturan main yang umum bagi peserta $(\mathrm{P})$ seperti: HP dinonaktifkan, datang tepat waktu, partisipasi aktif, tidak boleh menulis, mengikuti semua sesi, selalu senyum 227, dan bergembira dengan yel yel yang semangat dan menggugah. Antara lain: (T) Islam! (P) Rahmatan... Lil-'alamin. (T) Islam!! (P)Iman, ...Islam ....Ihsan.

Tahap kedua, dibuat slide langkah-langkah praktis Islam rahmatan lil-'alamin berdasarkan al-Qur'an dan as-Sunnah. Ada 
tiga langkah menjadikan Islam rahmatan lil-'alamin: 1) Islam sebagai konsepsi kehidupan, 2) Islam sebagai metode kehidupan, dan 3) Islam sebagai solusi berbagai problematika. Target dari materi 'Islam rahmatan lil-'alamin' adalah mahasiswa menyadari bahwa konsep Islamlah yang sesuai dengan fitrah penciptaan manusia. Pada poin "Islam sebagai metode kehidupan" targetnya mahasiswa memahami bahwa untuk bisa hidup sejahtera di dunia dan bahagia di akhirat dengan mengikuti yang sudah dicontohkan oleh Rasulullah SAW. Untuk lebih menarik pada setiap bagiannya bisa disisipi dengan film yang cocok.

Ketiga, tahap perenungan. Para mahasiswa dikondisikan agar sudah bersuci sejak permulaan acara. Doa dipimpin oleh dosen. Target dari sesi ini adalah agar para mahasiswa bertekad menjadikan Islam sebagai konsep dan metode kehidupan, sekaligus solusi dari berbagai masalah.

Agar ketiga prinsip pendidikan metode ini bisa terwujud, maka mahasiswa dilatih untuk beramal saleh dengan cara melakukan hidmah al-ummah (HU). Aktivitas HU ini merupakan kegiatan melayani masyarakat. HU bisa dilakukan secara individual maupun kolektif. Berdasarkan pengalaman, kegiatan HU yang dilakukan mahasiswa bentuknya beragam, antara lain: memakmurkan masjid, berkunjung ke panti asuhan, menyediakan makanan berbuka puasa, dan lain-lain.

Berdasarkan hasil laporan mahasiwa ada beberapa hikmah yang mereka dapat tatkala melaksanakan $\mathrm{HU}$ ke panti asuhan (PA), misalnya, bertambahnya nilai insaniyyah (kemanusiaan) ketika berkunjung ke PA. Mereka bisa berbagi harta, ilmu, pengalaman dengan anak-anak PA tanpa memandang suku atau agama. Pada saat bersamaan, bertambah pula nilai ruhiyah (semakin dekat dengan Allah) dengan bersyukur atas karunia Allah kepada mereka.

Selain ke PA, ada pula para mahasiswa yang memilih aktivitas HU dengan memakmurkan masjid. Kegiatan memakmurkan masjid dilakukan dengan berbagai cara, antara lain: membersihkan masjid dan sekitarnya, membimbing anak-anak belajar iqra', mewakafkan mushaf al-Qur'an, dan lain-lain. Adapun 
Tb. Chaeru Nugraha \& H.U. Jalaludin: Revitalisasi Nilai-nilai Agama Islam dalam PAI...

hikmah yang mereka peroleh adalah bertambahnya nilai ruhiyah, ahlaqiyah, dan insaniyah pada diri mereka. Keberhasilan pendampingan mahasiswa untuk mencapai ketiga prinsip MR sangat terkait dengan keteladan dosen dan para pementornya. Oleh karena itu, perlu dipersiapkan support system berupa berbagai kegiatan dan fasilitas yang menunjang beragam teknik pendidikan Islam.

\section{RAGAM TEKNIK PENDIDIKAN ISLAM}

Kita menyadari bahwa pembelajaran PAI tidak cukup hanya terjadi secara formal di ruang kelas yang terbatas pada jam pelajaran. Oleh karena itu, diperlukan kerja sama dengan masjid kampus. Para dosen mendapatkan support system yang mendukung pelaksanaan berbagai teknik PAI, antara lain melalui kegiatan: Paramadika (Panitia Ramadhan di Kampus), Panida (Panitia Idul Adha), PLM (Pesantren Liburan Mahasiswa), dan mentoring.

Secara informal, study club yang sudah terbentuk dipimpin para mentor yang sudah di-training menjadi para pendamping mahasiswa. Tujuan pendampingan mentor adalah menajamkan pemahaman kognitif PAI, membantu menghayati makna bacaan salat, dan berlatih dalam beramal saleh.

Teknik pembelajaran PAI dapat juga menggunakan situs internet, seperti pengalaman penulis dalam membuat blog PAI, yaitu: http://islamicstudiestb.wordpress.com/category/islamiceducation/first-lesson/.

Dengan media situs di internet, dosen bisa memahami tipetipe gaya belajar mahasiswa. Ada beberapa tipe gaya belajar mahasiswa. Pertama, tipe mujtami' (hobinya membaca). Untuk mengoptimalkan potensi mereka, difasilitasi dengan buku-buku referensi yang terkait. Kedua, tipe muraakiz (suka hal yang praktis). Untuk tipe kedua ini, kita siapkan power point berisi ringkasan materi. Ketiga, tipe mukhtalif (suka diskusi). Mahasiswa tipe ini tidak merasa cukup dengan diskusi di ruang kelas, sehingga bisa difasilitasi melalui konfirmasi via e-mail, SMS, atau chatting. Keempat, tipe mundamij (perlu dukungan). Tipe terakhir ini 


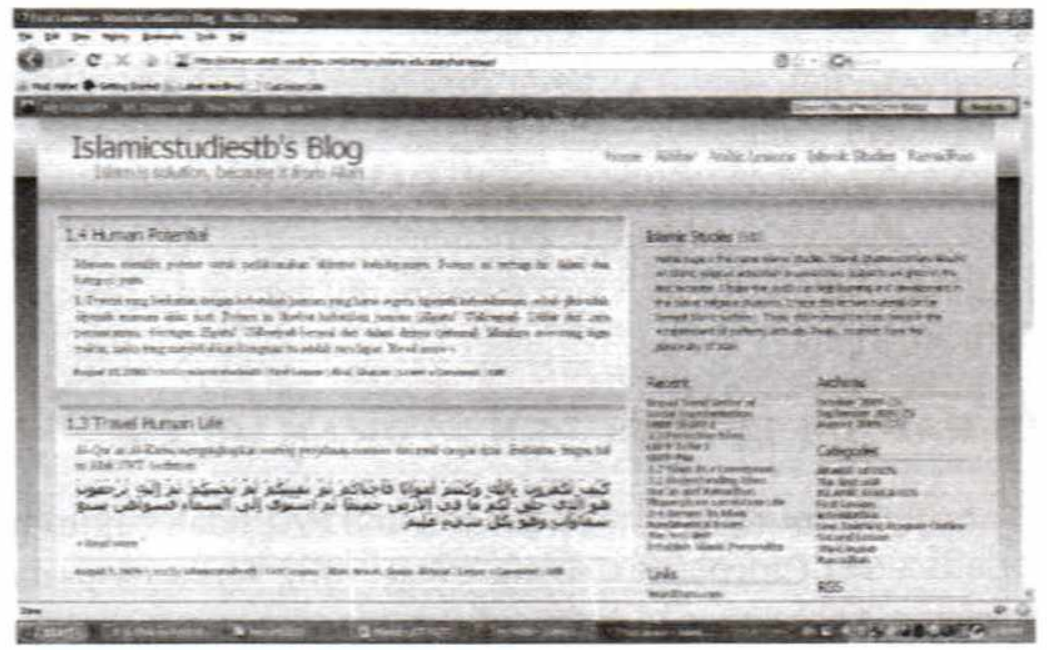

membutuhkan dosen yang sanggup berperan sebagai konsultan, yang memberikan motivasi life skill.

\section{E. KESIMPULAN}

Berdasarkan pengkajian konsep, metode, dan teknik nilai-nilai Islam masa Rasulullah (MR) dan mengkomparasikannya dengan masa kini (MK), penulis memperoleh jawaban atas masalah sosial budaya yang menjadi pemicu ketidakrukunan intra dan antar umat beragama. Pemicu masalah sosial budaya yang mendasar adalah adanya missing link paradigma akidah Islam; kurangnya pemahaman nilai-nilai Islam terpadu dan pengamalannya dalam kehidupan sehari-hari; dan kurangnya waktu komunikasi dinamis pendidik dan peserta didik.

Sebagai solusinya ada tiga langkah utama, yaitu: Pertama, masalah sosial budaya sangat dipengaruhi cara pandang terhadap kehidupan (view of life). Oleh karena itu, perlu pembelajaran paradigma akidah Islam sesuai dengan MR mencakup dimensi spirit dan dimensi realis. Dengan paradigma ini mahasiswa akan dibekali pola pikir Islami dan berpotensi untuk hidup berkah. Kedua, kehidupan penuh berkah memerlukan pemahaman terpadu tentang nilai-nilai Islam. Pada MR nilai-nilai Islam menjadi konsep dan metode kehidupan. Metode internalisasi nilai- 
nilai Islam pada MR mencakup aspek kognitif, afektif, dan psikomotorik.

Oleh Karena itu, pembelajaran PAI MK memerlukan metode terpadu (holistik, signifikan, dan aktif). Pada tataran praktis prinsip PAI MR bisa dicapai dengan berbagai metode, antara lain: metode training, metode diskusi, metode hidmah ummah, dan metode ceramah. Ketiga, untuk mengatasi keterbatasan waktu, variasi komunikasi dinamis dosen dan para mahasiswa dapat menggunakan berbagai teknik PAI, antara lain: kerja sama dengan masjid kampus, mentoring, dan WebCt (blog internet). Ketiga langkah utama inilah yang disebut dengan revitalisasi konsep, metode internalisasi terpadu, dan kreasi tektik PAI di PT.

\section{DAFTAR PUSTAKA}

Abu Rasytah. 2006. At-Taysîr fi Ushûil 't-Tafsîr. Beirut: Darul Ummah. Ash-Shobuny, M Ali.1989. Shafatu't- Tafasir. Beirut: Dar Al-Fikri.

Cohen L. dan Manion. 1994. Research Methods In Education. London: Routledge. Departemen Agama RI. 1982. Al-Qur'an dan Terjemahannya. Jakarta: Proyek

Pengadaan Penulisan Suci.

Departemen Pendidikan Nasional. 2005. Praktek Baik dalam Penjaminan Mutu

Pendidikan Tinggi (Buku I: Pembelajaran). Jakarta: Dikti.

Gayo, Iwan. 2002. Haji dan Umrah. Jakarta: Pustaka Warga Negara.

Hisyam, al-Mua'firy. 2004. As-Siratu 'n-Nabawiyatu li 'bni Hisyami, Terj.

Jakarta: Darul Falah.

Husain, Muhammad. 2002. Dirasah Fi al-Fikri al-Islam. Terj. Bogor: Pustaka

Thariqul Izzah.

Bangil: Al-Izzah.

Karli dkk. 2002. Implementasi Kurikulum Berbasis Kompetensi: Model-Model

Pembelajaran. Bandung: Bina Media Informasi.

Mansoer, Hamdan. 2006. Strategi Pengembangan MPK-PAI. Jakarta: Dikti.

Muhyidin. 2002. Al-Wafi fi Syarhi al-Arba'in An-Nawawiyah. Terjemahan oleh Abdullah. Jakarta: Rabbani Press.

Nabhani, Taqyudin. 2002. Syakhshiyyah Islamiyah Jilid II. Jakarta: HTI Press. Nugraha, Chaeru. 2010. Ayat Suci Lenyepaneun Media Pembangun Karakter Positif Urang Sunda'. Proceding Seminar Internasional Hari Bahasa Ibu. Bandung: Balai Bahasa Bandung. 
Tb. Chacru Nugraha \& H.U. Jalaludin: Revitalisasi Nilai-nilai Agama Islam dalam PAI...

2007. Intifaa'u 's-Sabakatu 'd-Dauliyah fii Tadriisi ' 1 Lughah 'F'Arabiyah. Proceding Seminar Intemasional Bahasa Arab. Bandung: LA Indonesia.

2006. Laporan Pelatihan Nasional Pengembangan Kepribadian Agama Islam. Yogyakarta: Inna Garuda.

Qahthan, Manna. 2001. Studi Ilmu-Ilmu Al-Qur'an. Jakarta: Litera Antar Nusa. Qol'ahiji. 1996. Qira'atu's- Siyasiyati li Sirati 'n-nabawiyati. Terj. Bangil: AlIzzah.

Shihab, Quraish. 2003. Membumikan Al-Qur'an. Bandung: Mizan.

Tim Dosen Agama Islam. 2007. Wawasan Al-Islam. Bandung: UPT Bidang Studi Unpad. 2009. Mata Kuliah Pengembangan Kepribadian: Agama Islam. Bandung: UPT Bidang Studi Unpad. http://localhost:81/ Lidwa Pusaka i-Software Kitab 9 Hadis http://www.depag.go.id/index.php?a=detilberita\&id=4148 Laporan wartawan KOMPAS

Imam Prihadiyoko, Kamis, 28 Mei 2009 (Kominfo-Newsroom), 31/12/2009 ]http:/islamicstudiestb.wordpress.com/category/islamic-education/first-lesson/ Maktabah Syamilah. 